\title{
Longitudinal changes in hyperinflation parameters and exercise capacity after giant bullous emphysema surgery
}

\author{
Rémi Neviere, MD, PhD, ${ }^{a}$ Michèle Catto, $\mathrm{MD},{ }^{\mathrm{b}}$ Nathalie Bautin, $\mathrm{MD},{ }^{a}$ Sophie Robin, MD, ${ }^{a}$ Henri Porte, MD, $\mathrm{PhD},{ }^{\mathrm{c}}$
} Jacques Desbordes, $\mathrm{MD}^{\mathrm{d}}$ and Régis Matran, $\mathrm{MD}, \mathrm{PhD}^{\mathrm{a}}$

From Explorations Fonctionnelles Respiratoires, Hôpital Calmette, CRHU Lille, France ${ }^{a}$; Centre "Cyr Voisin" Unité de Réhabilitation Respiratoire, $\mathrm{CH}$ Loos, France Clinique de Chirurgie Thoracique, Hôpital Calmette, CRHU Lille, France ${ }^{c}$; and Clinique d'Anesthésie Réanimation DAR, Hôpital Calmette, CRHU Lille, France. ${ }^{\mathrm{d}}$

No financial or other potential conflicts of interest regarding the contents of the submission exist.

Received for publication April 13, 2006; revisions received June 2, 2006; accepted for publication Aug 7, 2006.

Address for reprints: Professeur Remi Neviere, Explorations Fonctionnelles Respiratoires, Hôpital Calmette, CRHU Lille, France (E-mail: rneviere@univ-lille2.fr).

J Thorac Cardiovasc Surg 2006;132:1203-7

$0022-5223 / \$ 32.00$

Copyright $(\odot) 2006$ by The American Association for Thoracic Surgery

doi:10.1016/j.jtcvs.2006.08.002
Objective: Although resection of giant bullae for the purpose of improving the function of underlying compressed lung is an accepted form of surgery for emphysema, there is only limited information regarding long-term improvement in dynamic hyperinflation and exercise tolerance. Our major goal was to investigate the effects of lung resection for giant bullae on pulmonary function, dynamic hyperinflation, and exercise capacity in patients with chronic obstructive pulmonary disease characterized by emphysema.

Methods: Pulmonary function and exercise testing were assessed prospectively before and 3,6,12, 24, and 48 months after surgery in 12 patients who had chronic obstructive pulmonary disease with emphysema who underwent lung resection of giant bullae.

Results: Forced expiratory volume, diffusing capacity for carbon monoxide, arterial partial pressure of oxygen, and exercise capacity were significantly increased after resection of surgical bullae. Dynamic hyperinflation, as assessed by reduction in inspiratory capacity and dyspnea Borg scale, were significantly decreased during exercise. Improvement in baseline and exercise functional capacity slightly decreased over time, remaining, however, far above the value before surgery.

Conclusion: Altogether, these findings suggest that surgery for resection of giant bullae is an effective procedure for improving airflow, limiting gas exchange, and limiting exercise dynamic hyperinflation over time.

$\mathrm{T}$ The resection of giant bullae in patients with chronic obstructive pulmonary disease $(\mathrm{COPD})^{1-3}$ for the purpose of improving the function of underlying compressed lung is an accepted form of surgery for emphysema. ${ }^{4,5}$ Patients with COPD who have bullae occupying up to $30 \%$ of the hemithorax, with evidence of compressed lung tissue underlying the bullae, usually undergo surgery. Outcomes in carefully selected patients appear to be positive, with surgical mortality ranging from $0 \%$ to $22.5 \% .{ }^{6,7}$ Lung function testing at rest demonstrates early improvement of dyspnea and increases in forced expiratory volume in 1 second $\left(\mathrm{FEV}_{1}\right)$, ratio of forced expiratory volume in 1 second to forced vital capacity $\left(\mathrm{FEV}_{1} / \mathrm{FVC}\right)$, and diffusing capacity of the lung for carbon monoxide (DLCO). ${ }^{5,8,9}$ For example, in one of the largest series, long-term results of 84 patients who underwent surgical procedures for bullous emphysema indicate that the greatest improvement in $\mathrm{FEV}_{1}$, that is, $50 \%$ to $200 \%$, was seen in patients with bullae that occupied up to $50 \%$ of the hemithorax. ${ }^{5}$ Improvement in lung function appears durable in terms of symptom relief and pulmonary function testing., ${ }^{5,8,9}$

Elegant studies have recently reported that giant bullectomy appears to have been fairly safe and allowed clinical and functional improvement for years. ${ }^{8}$ This benefit of elective surgery in patients with giant bullous emphysema was evaluated in terms of dyspnea score, resting lung function, and quality of life. Although 6-minute walk 


\section{Abbreviations and Acronyms \\ $\mathrm{COPD}=$ chronic obstructive pulmonary disease \\ $\mathrm{DLCO}=$ diffusing capacity of the lung for carbon monoxide \\ $\mathrm{FEV}_{1}=$ forced expiratory volume in 1 second \\ $\mathrm{FVC}=$ forced vital capacity}

performance was evaluated in one study, improvement in baseline lung function and standardized exercise capacity have not been extensively investigated. Specifically, no information is available regarding long-term improvement in dynamic hyperinflation and exercise tolerance. The major objective of this 4-year follow-up prospective study was to investigate the effects of lung resection of giant bullae on pulmonary function, dynamic hyperinflation, and exercise capacity in patients with COPD characterized by emphysema.

\section{Methods}

\section{Patient Selection}

From May 2000 to December 2002, a total of 12 consecutive clinically stable patients who had COPD with severe emphysema participated in the study. All patients underwent evaluation and lung surgery at Calmette Hospital, a tertiary care hospital affiliated with Lille University School of Medicine. All research tests and protocols were approved by the human studies committee, and all patients provided informed consent for the studies and the operation. As previously reported, the patients with emphysema were markedly symptomatic with dyspnea according to the Borg scale ${ }^{10}$ greater than 2 (able to walk $<300 \mathrm{~m}$ ), despite optimal medical therapy. This included antibiotics, aerosol and oral bronchodilators, including short-acting and long-acting $\beta_{2}$-agonists, ipratropium bromide, corticosteroids, and repeated attempts at physical conditioning. Selection criteria for surgery (unilateral bullectomy) included the following: (1) unilateral large well-demarcated bullae (one third of the hemithorax), (2) anatomic emphysema and visible compression of adjacent lung tissue on computed tomographic scan of the thorax, (3) perfusion lung scintigraphy determining which areas are more affected by the emphysematous process, have impaired perfusion and ventilation, and therefore can be safely resected, and (4) absence of significant comorbid conditions.

\section{Study Design}

Patients were evaluated immediately before and approximately 3 , $6,12,24$, and 48 months after surgery. All of the patients were enrolled in a pulmonary rehabilitation program before surgery, whereas postoperative rehabilitation was not performed. During the follow-up period, patients were visited by the same pneumologist involved in the study, who decided on the best medical treatment. Medication use was standardized in each patient and included, if needed, inhaled steroids and mucolytic agents.

\section{Pulmonary Function Testing and Exercise Testing}

Pulmonary function testing was performed at the time of evaluation and after surgery. Tests were performed on a plethysmograph (MasterScreen Pneumo, Viasys, France) according to European and American Thoracic Society guidelines. ${ }^{11,12}$ Diffusion capacity was measured by the single breath technique. ${ }^{13}$ Patients underwent incremental (10 watts/min) maximal cycle ergometer exercise (Ergoline Medisoft Schiller, Wissembourg, France) to symptomlimited maximum. ${ }^{14}$ Changes in operating lung volumes were derived from dynamic inspiratory capacity at rest, every 3 minutes during exercise, and at peak exercise as previously described. ${ }^{14} \mathrm{On}$ a different day, a 6-minute walking test was performed. ${ }^{15}$

\section{Statistical Analysis}

For lung function and exercise capacity measurements, serial data were statistically analyzed by analysis of variance with repeated measures. Analysis of variance was performed after normal distribution testing. Multiple pairwise comparisons were performed with Bonferroni correction. All statistical analyses were conducted with a commercially available software program (Sigmastat, version 2.0; Jandel Co, San Raphael, Calif). Results are reported as mean \pm standard deviation. Exercise responses were studied by linear regression analysis of data from each individual, with slopes and intercepts expressed as means of these regression lines. Variables were compared at the same exercise time (isotime) determined by the patient's shortest exercise time during any exercise test.

\section{Results}

\section{Surgical Technique}

All 12 patients underwent the removal of giant bullae by unilateral lateral thoracotomy. Two patients underwent rightsided anatomic upper lobectomy and 10 patients underwent a nonanatomic resection. The nonanatomic resections were right-sided in 5 patients and left-sided in 5 patients. The average operative time was 90 minutes with no immediate complications in the early postoperative period.

\section{Clinical and Functional Responses}

All patients survived and were followed up for 4 years after removal of the bullae. Follow-up evaluations of breathlessness, pulmonary function, and exercise performance were conducted at $3.0 \pm 0.1,6.0 \pm 0.1,12.0 \pm 0.6,24.0 \pm 0.2$, and $48.0 \pm 0.2$ months. All patients were survivors with no missing clinical and functional assessment during the course of the study. Baseline pulmonary function testing demonstrated a study group of 12 male patients with severe airflow limitation, hyperinflation, and mildly reduced gas exchange (Tables 1 and 2). In this group of patients, no reversibility to $\beta_{2}$-agonists was observed. Resting hyperinflation was markedly reduced after surgery (Figure 1). DLCO and gas exchange efficacy were improved over the 4-year survey period (Table 2). Resting dyspnea Borg scale decreased after surgery (Table 2). 
TABLE 1. Baseline functional data and resting dyspnea score in patients treated for giant bullae

\begin{tabular}{|c|c|c|}
\hline Baseline & Value & Percent of predicted \\
\hline Age, y & $66 \pm 4$ & \\
\hline Pack-year tobacco smoking & $62 \pm 27$ & \\
\hline Male/female & $12 / 0$ & \\
\hline BMI $\left(\mathrm{kg} / \mathrm{m}^{2}\right)$ & $26.20 \pm 5.60$ & \\
\hline $\mathrm{FEV}_{1}(\mathrm{~L})$ & $1.12 \pm 0.16$ & $32 \pm 6 \%$ \\
\hline $\mathrm{FEV}_{1} / \mathrm{FVC}(\%)$ & $37 \pm 9 \%$ & \\
\hline $\mathrm{TLC}_{\text {pleth }}(\mathrm{L})$ & $7.6 \pm 1.8$ & $131 \pm 28 \%$ \\
\hline $\mathrm{FRC}_{\text {pleth }}(\mathrm{L})$ & $5.65 \pm 1.1$ & $155 \pm 25 \%$ \\
\hline $\mathrm{RV}_{\text {pleth }}(\mathrm{L})$ & $5.2 \pm 1.2$ & $226 \pm 36 \%$ \\
\hline $\mathrm{DLCO}\left(\mathrm{mL} \cdot \min ^{-1} \cdot \mathrm{mm} \mathrm{Hg}^{-1}\right)$ & $9.95 \pm 2.45$ & $57 \pm 24 \%$ \\
\hline $\mathrm{PaO}_{2}(\mathrm{~mm} \mathrm{Hg})$ & $67 \pm 8$ & \\
\hline $\mathrm{PaCO}_{2}(\mathrm{~mm} \mathrm{Hg})$ & $42.8 \pm 1.5$ & \\
\hline Dyspnea (Borg scale) $>2$ & $100 \%$ & \\
\hline
\end{tabular}

Values are mean $\pm \mathrm{SD}$. BMI, Body mass index; $F E V_{1}$, forced expiratory volume in 1 second; $F V C$, forced vital capacity; $T L C$, total lung capacity; $F R C$, functional residual capacity; $R V$, residual volume; $D L C O$, diffusing capacity of the lung for carbon monoxide; $\mathrm{PaO}_{2}$, arterial partial pressure of oxygen; $\mathrm{PaCO}_{2}$, arterial partial pressure of carbon dioxide; pleth, plethysmography.

\section{Exercise Response and Cardiopulmonary}

Exercise Testing

Compared with preoperative values for the 6-minute walking distance $(787 \pm 269$ feet; $240 \pm 82 \mathrm{~m})$, significant improvement was noted 3, 6, 12, 24, and 48 months after the operation (ie, $45 \%, 40 \%, 32 \%, 33 \%$, and $25 \%$, respectively). Results of cardiopulmonary exercise testing 48 months after surgery indicated increases in total exercise time $(6.0 \pm 2.5$ minutes vs $10.1 \pm 1.8$ minutes; $P<.05)$ and peak oxygen uptake $\left(12 \pm 3 \mathrm{~mL} \cdot \mathrm{kg}^{-1} \cdot \mathrm{min}^{-1} \mathrm{vs} 16 \pm\right.$ $\left.2 \mathrm{~mL} \cdot \mathrm{kg}^{-1} \cdot \min ^{-1} ; P<.05\right)$ compared with preoperative values. Maximum minute ventilation was higher $(40 \pm 8$ $\mathrm{L} / \mathrm{min}$ vs $50 \pm 8 \mathrm{~L} / \mathrm{min} ; P<.05$ ), and the pattern of breathing changed postoperatively, with lower maximum breathing frequency $(47 \pm 7 / \mathrm{min}$ vs $35 \pm 5 / \mathrm{min} ; P<.05)$

\section{Resting lung hyperinflation parameters}

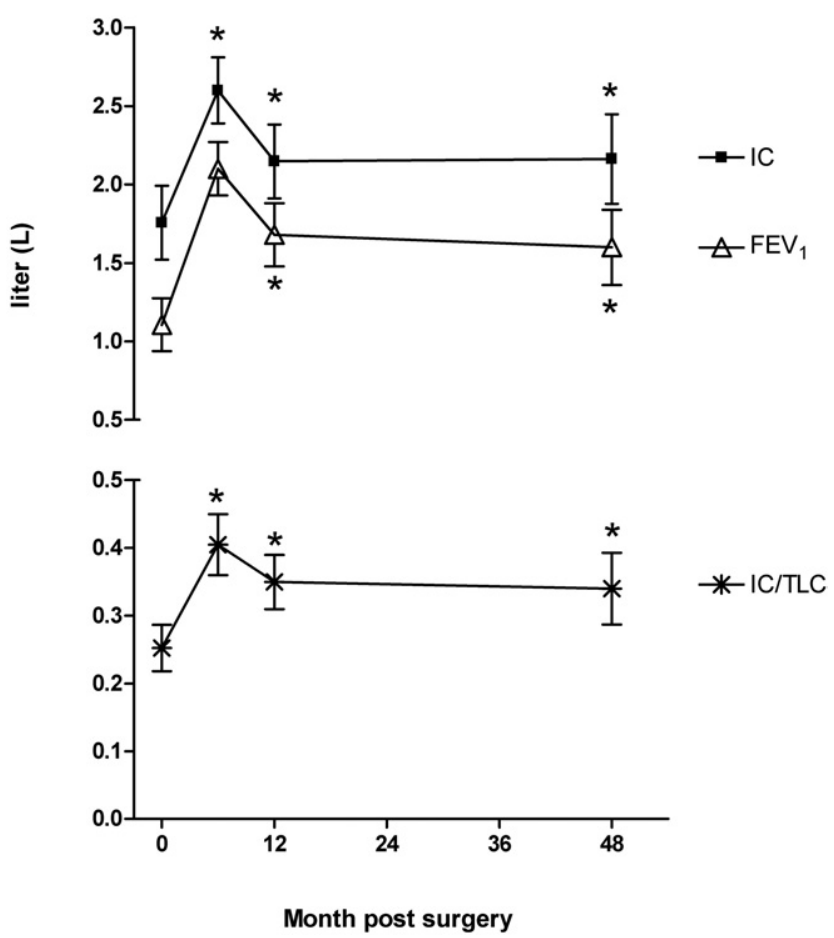

Figure 1. Resting pulmonary function testing at baseline and after lung resestion surgery in all 12 patients. Forced expiratory volume in 1 second (FEV $)_{1}$, inspiratory capacity (IC), and inspiratory capacity/total lung capacity (IC/TLC) are presented as mean \pm SD. ${ }^{*} \boldsymbol{P}<.05$ compared with controls (values before surgery).

and higher maximal tidal volume $(1.1 \pm 0.7 \mathrm{~L} / \mathrm{min}$ vs $1.4 \pm$ $0.8 \mathrm{~L} / \mathrm{min} ; P<.05)$ at peak exercise. Maximum heart rate did not significantly change despite patients being able to reach higher oxygen uptake after surgery. Compared with preoperative values, the Borg scale at peak exercise was

TABLE 2. Resting pulmonary function testing at baseline and 3,6, 12, 24 and 48 months after lung resection surgery

\begin{tabular}{|c|c|c|c|c|c|c|}
\hline Variables at rest & Baseline & $3 \mathrm{mo}$ & $6 \mathrm{mo}$ & $12 \mathrm{mo}$ & $24 \mathrm{mo}$ & $48 \mathrm{mo}$ \\
\hline $\mathrm{FEV}_{1}(\%$ predicted $)$ & $32 \pm 6$ & $59 \pm 2$ & $51 \pm 6$ & $50 \pm 6$ & $49 \pm 3$ & $50 \pm 3$ \\
\hline $\mathrm{FEV}_{1} / \mathrm{FVC}(\%)$ & $37 \pm 9$ & $42 \pm 2$ & $38 \pm 5$ & $42 \pm 6$ & $33 \pm 6$ & $35 \pm 3$ \\
\hline TLC (\% predicted) & $131 \pm 28$ & $90 \pm 12$ & $91 \pm 9$ & $92 \pm 13$ & $101 \pm 27$ & $120 \pm 14$ \\
\hline $\mathrm{FRC}_{\text {pleth }}(\%$ predicted) & $155 \pm 25$ & $105 \pm 10$ & $110 \pm 20$ & $112 \pm 18$ & $118 \pm 12$ & $116 \pm 18$ \\
\hline $\mathrm{RV}_{\text {pleth }}(\%$ predicted $)$ & $226 \pm 36$ & $87 \pm 23$ & $112 \pm 22$ & $118 \pm 30$ & $140 \pm 17$ & $155 \pm 35$ \\
\hline DLCO (\% predicted) & $57 \pm 24$ & $88 \pm 2$ & $78 \pm 5$ & $78 \pm 6$ & $72 \pm 6$ & $68 \pm 9$ \\
\hline $\mathrm{PaO}_{2}(\mathrm{~mm} \mathrm{Hg})$ & $67 \pm 8$ & $78 \pm 2$ & $74 \pm 5$ & $78 \pm 8$ & $77 \pm 8$ & $72 \pm 6$ \\
\hline $\mathrm{PaCO}_{2}(\mathrm{~mm} \mathrm{Hg})$ & $42.8 \pm 1.5$ & $41.2 \pm 1.2$ & $41.3 \pm 1.3$ & $42.3 \pm 0.8$ & $40.0 \pm 1.9$ & $42.1 \pm 1.8$ \\
\hline Borg scale & $2.8 \pm 0.6$ & $1.2 \pm 0.6$ & $1.8 \pm 0.7$ & $1.4 \pm 0.2$ & $1.4 \pm 0.6$ & $1.2 \pm 0.8$ \\
\hline
\end{tabular}

Values are mean $\pm S D$. $F E V$, forced expiratory volume in 1 second; $F V C$, forced vital capacity; $T L C$, total lung capacity; $F R C$, functional residual capacity; $R V$, residual volume; $D L C O$, diffusing capacity of the lung for carbon monoxide; $\mathrm{PaO}_{2}$, arterial partial pressure of oxygen; $\mathrm{PaCO}_{2}$, arterial partial pressure of carbon dioxide; pleth, plethysmography. 


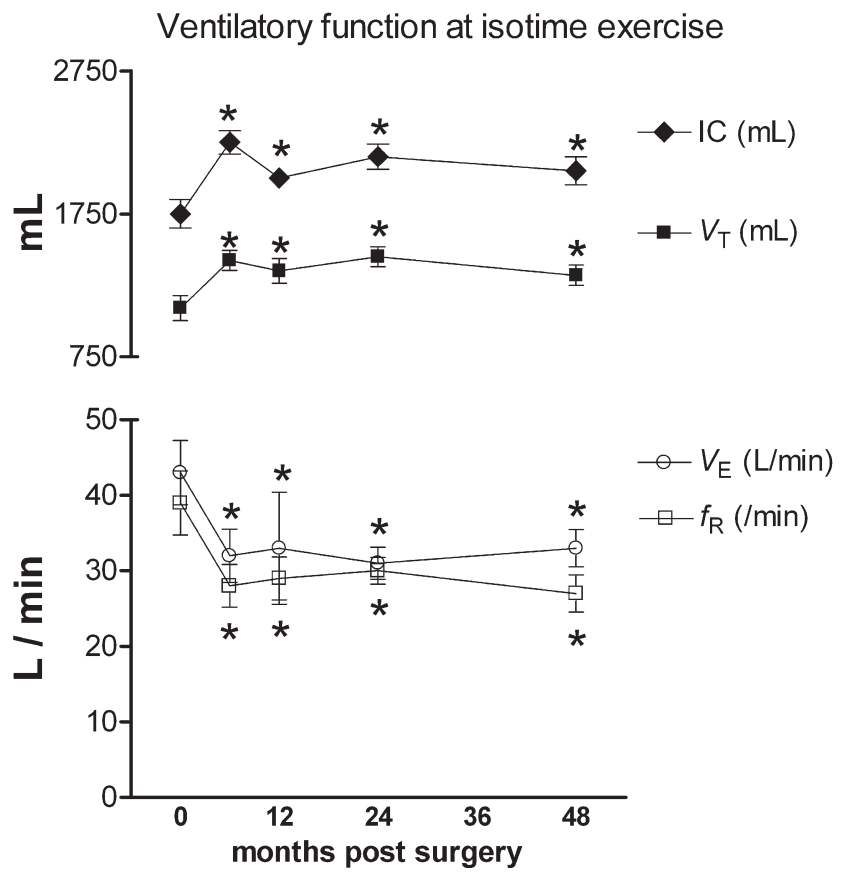

Figure 2. Ventilatory response during exercise at exercise isotime before and after surgery in all 12 patients. Tidal volume $\left(V_{T}\right)$ and dynamic inspiratory capacity (IC) were significantly increased after surgery (top). Minute ventilation $\left(V_{E}\right)$ and breathing frequency $\left(f_{R}\right)$ were significantly reduced after surgery (bottom). Results are mean \pm SD. ${ }^{*} \boldsymbol{P}<.05$ compared with controls (values before surgery).

lower 48 months after surgery $(6.0 \pm 1.2$ vs $3.1 \pm 0.4)$. For purposes of comparison, outcome results were functional variables at end-exercise isotime. Isotime was the highest equivalent exercise endurance time between the two ergocycle exercise periods. Functional variables were analyzed at isotime exercise before and after surgery to approximate the same workload (Figures 2 and 3).

\section{Discussion}

The major result of this study is that elective surgery for the treatment of giant bullae in selected patients improves clinical and lung functional conditions both at rest and during standardized exercise testing. Baseline $\mathrm{FEV}_{1}$, DLCO, and arterial partial pressure of oxygen were significantly increased after surgery for giant bullae. Exercise capacity increased after unilateral resection of bullae, which was associated with reduction in dynamic hyperinflation and alveolar/arterial partial pressure of oxygen gradient. Improvement in these baseline and exercise functional tests slightly decreased over the 4-year follow-up period, remaining, however, far better than values before the operation.

A key element in dyspnea, ventilation, and exercise capacity limitation in patients with COPD is occurrence of

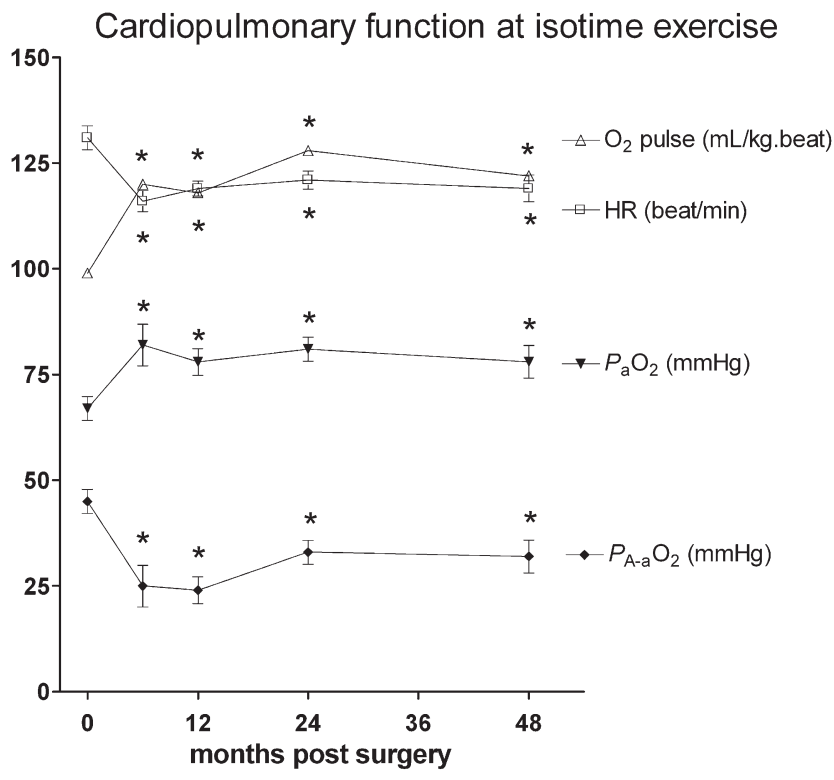

Figure 3. Cardiovascular and respiratory response during exercise at exercise isotime before and after surgery in all 12 patients. Heart rate $(\mathrm{HR})$ was lower and oxygen $\left(\mathrm{O}_{2}\right)$ pulse was higher at a given workload after surgery compared with baseline testing (top). Arterial blood gas analysis showed that arterial partial pressure of oxygen $\mathrm{PaO}_{2}$ and alveolar to arterial partial pressure $\mathbf{P}_{\mathrm{A}-\mathrm{a}} \mathbf{0}_{2}$ gradient at a given workload were higher after surgery compared with baseline testing (bottom). Results are mean $\pm S D ;{ }^{*} P<.05$ compared with controls (values before surgery).

dynamic hyperinflation, in which expiratory flow limitation leads to progressive increases in end-expiratory lung volume and restriction in tidal volume. ${ }^{16,17}$ However, duration of such an improvement in dynamic hyperinflation and lung function is largely unknown because long-term clinical and functional follow-up is difficult to summarize owing to incomplete reporting and multiple methods of data presentation. ${ }^{1-5}$ In accordance with previous studies, ${ }^{1-5,8,9}$ we observed a significant improvement in resting lung function in patients with COPD selected for lung surgery to resect giant bullae. Compared with preoperative baseline, spirometric and plethysmographic results demonstrated a reduction in both total lung capacity and residual volume, but more so in the latter, such that functional residual capacity and inspiratory capacity increased. After initial postoperative procedures, stable values of intrathoracic lung volume, as reflected by plethysmographic functional residual capacity measurements, support the contention that no new lung distention developed. On the other hand, improvement in $\mathrm{FEV}_{1}$ and $\mathrm{FEV}_{1} / \mathrm{FVC}$ ratio may reflect reduced bronchial obstruction, which may be related to the mechanical effects of bullectomy. Removal of giant bullae may indeed decom- 
press the functioning lung and the ipsilateral bronchi, with improvement in lung elastic recoil reducing flow limitation. In addition, bullectomy may reduce inhomogeneity of gas mixing and increase in pulmonary capillary volume owing to improvement in cardiac function. Indeed, recruitment of previously compressed alveolar units and additional capillaries of the healthier lung may represent important determinant factors in diffusing capacity improvement after lung volume reduction surgery. ${ }^{4,9}$ Our findings that DLCO improved is consistent with studies showing that trend to increase after surgical ${ }^{18}$ and bronchoscopic ${ }^{19}$ lung volume reduction.

Lung resection for giant bullae significantly increased patient aerobic capacity, which could be mainly the result of dynamic hyperinflation reduction and improved hemoglobin oxygen saturation during incremental maximal cycle ergometer exercise. In our study, dynamic inspiratory capacity increased in all patients, and this improvement was sustained 12, 24, and 48 months postoperatively. Moreover, during exercise, the degree of hemoglobin oxygen desaturation was significantly reduced after surgery. Improvements in arterial oxygenation may be attributed to enhanced ventilation-perfusion relationships after the recruitment of previously compressed lung that comprised normally perfused alveolar units. ${ }^{4,6,7,9}$ It is thus likely that improvement in exercise performance may also be related to increase in arterial oxygen content. Reduced dynamic hyperinflation, which facilitates venous return, may also facilitate increases in cardiac output and oxygen pulse during exercise. ${ }^{20-22}$ Altogether, improvements in dynamic hyperinflation and oxygen saturation result in increased peripheral oxygen delivery that is reflected by increased oxygen pulse.

In summary, this investigation clearly demonstrates that lung resection for giant bullae in selected patients improves lung function and exercise performance. In our patients, improvement in aerobic capacity could be mainly related to reduction in dynamic hyperinflation and oxygen desaturation during incremental maximal cycle ergometer exercise. Although results of baseline spirometry, lung function, and exercise capacity slightly decreased over the 4-year follow-up period, these functional parameters remained far above the value before surgery.

\section{References}

1. Potgieter PD, Benatar SR, Hewitson RP, Ferguson AD. Surgical treatment of bullous lung disease. Thorax. 1981;36:885-90.
2. Laros CD, Gelissen HJ, Bergstein PG, Van den Bosch JM, Vanderschueren RG, Westermann CJ, et al. Bullectomy for giant bullae in emphysema. J Thorac Cardiovasc Surg. 1986;91:63-70.

3. Connolly JE. Results of bullectomy. Chest Surg Clin N Am. 1995;5: 765-76.

4. O'Donnell DE, Webb KA, Bertley JC, Chau LK, Conlan AA. Mechanisms of relief of exertional breathlessness following unilateral bullectomy and lung volume reduction surgery in emphysema. Chest. 1996;110:18-27.

5. FitzGerald MX, Keelan PJ, Cugell DW, Gaensler EA. Long-term results of surgery for bullous emphysema. J Thorac Cardiovasc Surg. 1974;68:566-87.

6. Benditt JO. Surgical therapies for chronic obstructive pulmonary disease. Respir Care. 2004;49:53-61.

7. Meyers BF, Patterson GA. Chronic obstructive pulmonary disease. 10: Bullectomy, lung volume reduction surgery, and transplantation for patients with chronic obstructive pulmonary disease. Thorax. 2003;58: 634-8.

8. Palla A, Desideri M, Rossi G, Bardi G, Mazzantini D, Mussi A, et al. Elective surgery for giant bullous emphysema: a 5-year clinical and functional follow-up. Chest. 2005;128:2043-50.

9. Schipper PH, Meyers BF, Battafarano RJ, Guthrie TJ, Patterson GA, Cooper JD. Outcomes after resection of giant emphysematous bullae. Ann Thorac Surg. 2004;78:976-82.

10. Borg G, Hassmen P, Lagerstrom M. Perceived exertion related to heart rate and blood lactate during arm and leg exercise. Eur J Appl Physiol Occup Physiol. 1987;56:679-85.

11. Miller MR, Hankinson J, Brusasco V, Burgos F, Casaburi R, Coates A, et al. Standardisation of spirometry. Eur Respir J. 2005;26:319-38.

12. Wanger J, Clausen JL, Coates A, Pedersen OF, Brusasco V, Burgos F, et al. Standardisation of the measurement of lung volumes. Eur Respir J. 2005;26:511-22.

13. Macintyre N, Crapo RO, Viegi G, Johnson DC, van der Grinten CP, Brusasco V, et al. Standardisation of the single-breath determination of carbon monoxide uptake in the lung. Eur Respir J. 2005;26:720-35.

14. ATS/ACCP Statement on cardiopulmonary exercise testing. Am J Respir Crit Care Med. 2003;167:211-77.

15. Enright PL. The six-minute walk test. Respir Care. 2003;48:783-5.

16. O'Donnell DE. Breathlessness in patients with chronic airflow limitation. Mechanisms and management. Chest. 1994;106:904-12.

17. O'Donnell DE. Ventilatory limitations in chronic obstructive pulmonary disease. Med Sci Sports Exerc. 2001;33:S647-55.

18. Meyers BF, Yusen RD, Guthrie TJ, Patterson GA, Lefrak SS, Davis $\mathrm{GE}$, et al. Results of lung volume reduction surgery in patients meeting a national emphysema treatment trial high-risk criterion. J Thorac Cardiovasc Surg. 2004;127:829-35.

19. Hopkinson NS, Toma TP, Hansell DM, Goldstraw P, Moxham J, Geddes DM, et al. Effect of bronchoscopic lung volume reduction on dynamic hyperinflation and exercise in emphysema. Am J Respir Crit Care Med. 2005;171:453-60.

20. Benditt JO, Lewis S, Wood DE, Klima L, Albert RK. Lung volume reduction surgery improves maximal $\mathrm{O} 2$ consumption, maximal minute ventilation, $\mathrm{O} 2$ pulse, and dead space-to-tidal volume ratio during leg cycle ergometry. Am J Respir Crit Care Med. 1997;156:561-6.

21. Cordova F, O’Brien G, Furukawa S, Kuzma AM, Travaline J, Criner GJ. Stability of improvements in exercise performance and quality of life following bilateral lung volume reduction surgery in severe COPD. Chest. 1997;112:907-15.

22. Mineo TC, Pompeo E, Rogliani P, Dauri M, Turani F, Bollero P, et al. Effect of lung volume reduction surgery for severe emphysema on right ventricular function. Am J Respir Crit Care Med. 2002;165:489-94. 